\title{
DESCRIPTIONS OF THREE NEW SPECIES OF DIPARA WALKER (HYMENOPTERA: PTEROMALIDAE) FROM INDIA
}

\author{
T.C. Narendran ${ }^{1}$ and P.M. Sureshan ${ }^{2}$ \\ ${ }^{1}$ Systematic Entomology Laboratory, Department of Zoology, University of Calicut, Kozhikode, Kerala 673635, India. \\ Email: narendra@unical.ac.in \\ ${ }^{2}$ Zoological Survey of India, Western Ghats Field Research Station, Kamala Building, Annie Hall Road, Kozhikode, Kerala 673002, India.
}

\begin{abstract}
Three new species viz. Dipara keralensis sp. nov., Dipara miniae sp. nov. and Dipara mohanae sp. nov. are described. A key for the identification of these species of Dipara from India is also provided.
\end{abstract}

Keywords

Hymenoptera, Pteromalidae, Dipara, new species, India

$\begin{array}{lr}\text { F1 to F7 - Funicular segments one to seven } & \text { Abbreviations } \\ \text { OOL - Ocellocular line } & \text { MV - Marginal vein } \\ \text { POL - Postocellar line } & \text { PMV - Postmarginal vein } \\ \text { STV - Stigmal vein } & \text { SMV - Submarginal vein } \\ & \text { ZSIC - Zoological Survey of India, Calicut (Kozhikode) }\end{array}$

\section{Introduction}

Walker (1883) erected the genus Dipara with the type species Dipara petiolata Walker. Graham (1969), Hedqvist (1969) and Boucek (1988) listed the synonyms of Dipara Walker. Members of this genus are found distributed in North America, Europe, Africa, South Asia and Australia. So far no species has been reported (published) from the Oriental Region under the genus Dipara except for the report of an undetermined species from Sri Lanka by Boucek et al. (1978) and Farooqi and Subba Rao (1986). Till date this species has remained undetermined or unpublished and the specimen(s) of this undetermined species are not available to us for our studies. Boucek (1988) estimated (probably based on unpublished records) that at least three species occur in South Asia, three species in North America, one species in Europe, at least three species in Africa and 3-4 species in Australia. In this paper we describe three new species of Dipara from Kerala. A key to Indian species of the genus is also provided.
Received on 20 September 2000

Accepted on 31 January 2001
The genus Dipara is characterised as follows: Mandibles tridentate; antenna 13 segmented (11173); antenna inserted clearly below middle of frons; notauli complete, rather wide apart, almost straight; scutum even posteriorly pilose; scutellum with frenum; propodeum with nucha and incomplete plica; mostly brachypterous, rarely macropterous. Boucek (1988) stated that females of known non-Australian Dipara are always subapterous but Australian females available for studies have the wings at least in one species (hyalinipennis) developed in various grades from short stumps to almost full size. In Indian species also, the wings of females are subapterous in keralensis and mohanae whereas in the case of female of miniae the wings are macropterous. The bristles of the scutum are far removed from the transcutal line in the Indian species as in the case of most other non-Australian species. 


\section{Dipara keralensis sp. nov.}

(Fig. 1-2)

\section{Material examined}

Holotype: Female, 2.ix.1995, Parambikulam, Kerala, Coll. P.M. Sureshan (\# ZSIC865).

Paratype: Female, 4.ix.2000, Calicut University Campus, Kerala, Coll. T.C. Narendran (\# ZSIC857).

\section{Distribution}

Parambikulam (Kerala) 10 $0^{\circ} 24^{\prime}$ Latitude and $76^{\circ} 47^{\prime}$ 'Longitude. Calicut University campus, Kozhikode $11^{\circ} 13^{\prime}$ Latitude $75^{\circ} 48^{\prime}$ Longitude. The specimens were collected by using sweep nets from forest area in Parambikulam and mixed crop area in Calicut University Campus.

\section{Etymology}

The species is named after Kerala state.

\section{Diagnostic characters}

Female: Length $2.47 \mathrm{~mm}$. Head blackish-brown with areas near mouth slightly paler; mandible pale brownish-yellow with paler apex; antennal scape yellowish-brown with basal one-third darker; pedicel, anellus and F1 pale brownish-yellow. F2, F3, F4 and F5 blackish-brown; F6, F7 and clava whitish-yellow; mesosoma honey brown with mesopleura, a median narrow part of mesoscutum, sides of scutellum, propodeal nucha paler; tarsi pale brownish yellow; pretarsus brown. Mid leg honey brown except pale apex of tibia and tarsi. Hind coxa pale yellowishwhite, rest of hind legs pale brownish-yellow with apical half of femur slightly darker dorsolaterally. Setae on head and mesosoma brown. Metasoma; Petiole pale yellow with base brown; rest of metasoma brownish-black with epipygium mostly pale yellow with its base and apex darkish.

Head: Broader than mesosoma in dorsal view (13:8); frons reticulate head in anterior view slightly wider than its length (18:17); eyes slightly diverging on lower side; POL equal to OOL; clypeus slightly longer than wide; gena posteriorly rounded; malar sulcus distinct; maximum diameter of eye in profile about $3 x$ length of malar space; face below antennal toruli punctate and with small setae; vertex with three pairs of setae: one pair each near eye margin on either side and third pair behind hind ocelli; anterior pair of setae directed forwards, remaining setae directed slightly backwards; occiput abruptly vertical and concave. Scrobe shallow, hardly demarcated from parascrobal

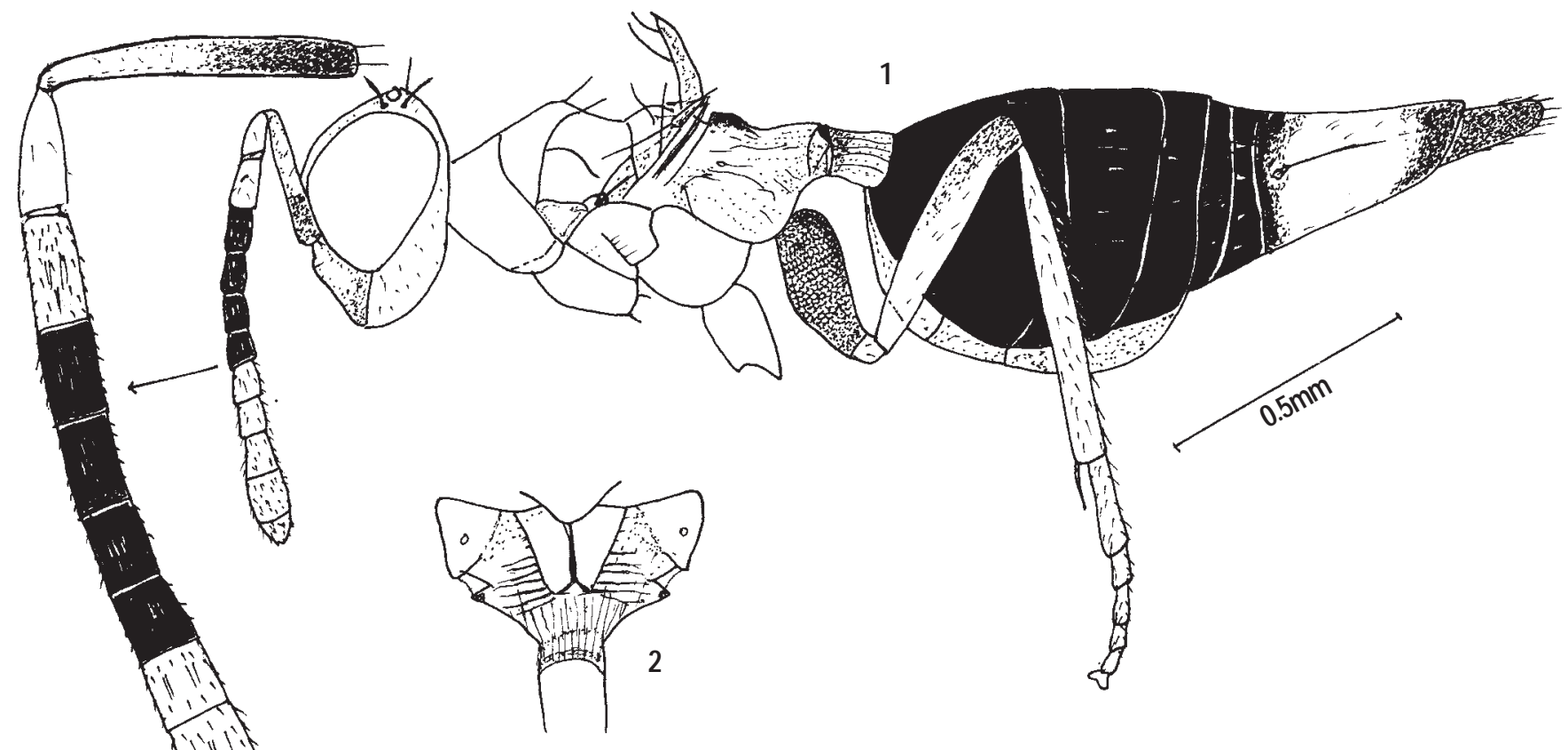

Figures 1-2. Dipara keralensis sp. nov. (female) 1. Body profile; 2. Propodeum 
area uniformly reticulate as in parascrobal area. Antenna inserted at level of ventral margin of eyes. Antennal formula, 11173. Relative measurements of antennal segments (length:width); Scape $=49: 6 ;$ Pedicel $=19: 7 ; \mathrm{F} 1=17: 8 ; \mathrm{F} 2=14.5: 9 ; \mathrm{F} 3=14.8: 8 ; \mathrm{F} 4$ $=14: 8 ; \mathrm{F} 5=11: 10 ; \mathrm{F} 6=11: 10.5 ; \mathrm{F} 7=13: 12 ;$ Clava $=34: 12$.

Mesosoma: Pronotum and anterior part of mesonotum reticulate; pronotum $2 \mathrm{x}$ as wide as long; mesoscutum with two setae; scapula with a strong seta on outer margin; mesoscutum $2 \mathrm{x}$ as long as scutellum; notauli complete; scutellum with two pairs of strong setae, with frenum; area behind frenum mostly smooth with faint longitudinal aciculations; area in front of frenum finely reticulate; prepectus mostly smooth; propodeum constricted posteriorly to form a nucha, $1.5 \mathrm{x}$ as long as scutellum; propodeum with a maiden raised complete carina and raised plicae (Fig. 2); Hind tibial spur half as long as combined length of rest of tarsal segments. Wings short (brachypterous), reaching base of petiole; forewing with five setae in addition to another seta at the meeting of tegula.

Metasoma: Petiole 1.2x as long as broad in dorsal view; remaining part shagreened, with two pairs of long setae, one each from each circus; metasoma length $1.9 \mathrm{x}$ as long as mesosoma; $\mathrm{T} 1$ slightly shorter than epipygium, $2 \mathrm{x}$ as long as $\mathrm{T} 2$, following tergites gradually decreasing in size.

Male: Unknown.

Host: Unknown.

\section{Discussion}

This new species comes close to Dipara nigrita Hedqvist in having propodeum with complete median carina and head wider than mesosoma. However D. nigrita differs from D. keralensis in having forewing with nine strong setae (in keralensis forewing with 5 setae), vertex with blue metallic tint (in keralensis without metallic tint), pedicel anelus and funicle segments uniformly brown (in keralensis pedicel, anellus and F1 pale brownishyellow with F2, F3, F4 \& F5 blackish-brown) and hind coxa dark brown (in keralensis hind coxa pale yellowish-white).

\section{Current status of habitat}

The forest area from where the collections were made are mostly undisturbed, where as the mixed crop area of Calicut University campus is mostly disturbed by human interference.

\section{Dipara miniae sp. nov.}

(Figs. 3-6)

\section{Material examined}

Holotype: Female, 13.xii.1987, Chindaki, Kerala, Coll. T.C. Narendran and party (\# ZSIC863).

\section{Distribution}

Chindaki (Kerala) 10 $24^{\prime}$ 'Latitude, $76^{\circ} 47^{\prime}$ longitude. The specimen was collected by sweep net from semiforest area

\section{Etymology}

The species is named after Dr. T.V. Mini for her assistance in our research on Pteromalidae.

\section{Diagnostic characters}

Female: Length $1.9 \mathrm{~mm}$. Head and mesosoma honey brown with lower face and clypeus and lower ends of gena paler; mandibles pale brownish-yellow with apices darker; eye grey with large black spot; antennae pale yellow with apex of F4, F5 and F6 darker (Fig. 3); ocelli dark brown. Fore coxa pale yellowishwhite; fore trochanter, fore tibia and fore tarsi pale brownish yellow; fore femur yellowish-brown. mid legs yellowish-brown with trochanter, tibia and tarsi paler. Hind leg pale whitish-yellow with femur slightly darker towards apex. Setae on head, mesosoma and on wings black; pubescence pale yellow. Wings hyaline with tree dark infuscations (Fig. 4). Metasoma with petiole pale yellow with base honey brown, remaining part of metasoma honey brown with paler colour on sides of $\mathrm{T} 1$ and epipygium (Fig. 3).

Head: Broader than mesosoma in dorsal view (11:9); head in anterior view a little more than $1.2 x$ its length; eyes not distinctly diverging on ventral side; POL 2x OOL; clypeus $1.4 \mathrm{x}$ as wide as long; gena posteriorly rounded; malar sulcus distinct; maximum diameter of eye $3.25 x$ length of malar space; face below antennal toruli weakly reticulate; frons and scrobe reticulate-striate; scrobe deep, not reaching front ocellus; vertex with three pairs of setae, two pairs near eyes and one pair behind hind ocelli; occiput vertical and slightly concave. Antenna inserted at level of ventral margin of eyes. Antennal formula 1173. Relative measurements of antennal segments (length:width) -- Scape $=$ 42:12; Pedicel $=14: 6 ; \mathrm{F} 1=9: 7 ; \mathrm{F} 2=10: 6 ; \mathrm{F} 3=11: 6 ; \mathrm{F} 4=8: 7 ; \mathrm{F} 5$ $=8: 8 ; \mathrm{F} 6=10: 8 ; \mathrm{F} 7=14: 10 ;$ Clava $=26: 10$.

Mesosoma: pronotum and anterior part of mesonotum transversly striate-reticulate; pronotum about $3 \mathrm{x}$ as wide as long; mesoscutum with two strong setae in the middle; each scapula with a seta on its outer margin; Mesoscutum 1.6x length of scutellum; notauli complete; scutellum with two pairs of strong setae; area behind frenum mostly smooth with faint longitudinal striae; area in front of frenum distinctly reticulate; prepectus smooth; propodeum almost as long as scutellum, with a distinct 


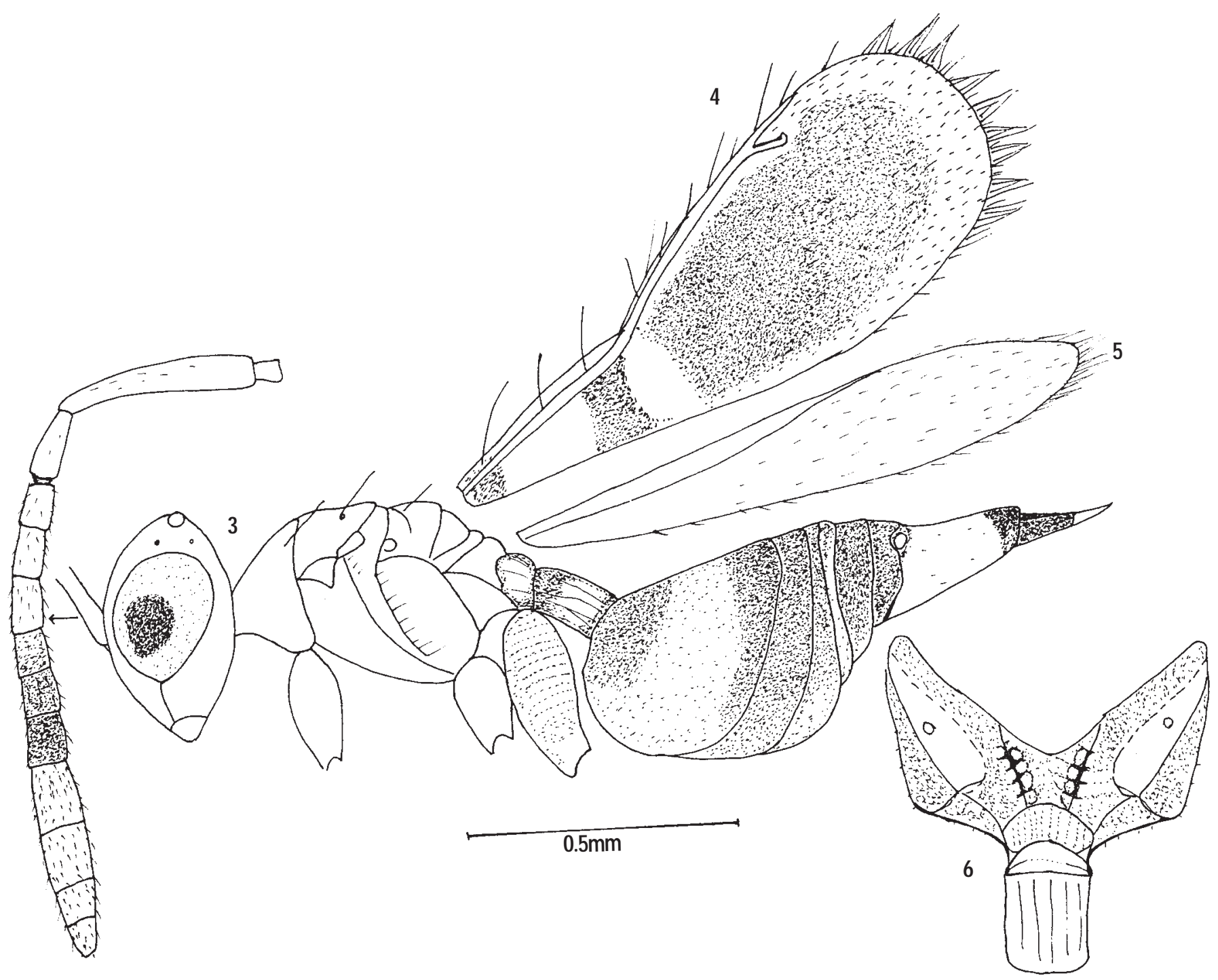

Figures 3-6. Dipara miniae sp. nov. (female)

3. Body profile; 4. Forewing; 5. Hind wing; 6. Propodeum

short nucha and without median carina; plicae present (Fig. 6); hind tibial spur slightly shorter than half length of hind metatarsus, the latter $1.4 \mathrm{x}$ length of remaining tarsal segments combines. Macropterous; length of forewing a little less than $2.8 \mathrm{x}$ its maximum width. Relative lengths of forewing veins: $\mathrm{SMV}=46 ; \mathrm{MV}=49 ; \mathrm{PMV}=15 ; \mathrm{STV}=7$.

Metasoma: Smooth; petiole a little more than $1.5 \mathrm{x}$ as long as its width in dorsal view; length of metasoma about $2 x$ length of mesosoma in profile; $\mathrm{T} 1$ largest, as long as combined length of $\mathrm{T} 4$ to distal margin of epipygium.
Male: Unknown

Host: Unknown

\section{Discussion}

This new species resembles Dipara hyalinipennis (Girault) in having fully developed wings and in having area in front of frenum distinctly reticulate. However $D$. hyalinipennis differs from miniae in having: 1 . Propodeum with short median carina (in miniae without median carina); 2. Sublateral carina incomplete on propodeum (in miniae propodeum with complete sublateral carinae); 3 . Petiole $1.3 \mathrm{x}$ as long as its width (in miniae petiole a 
little more than 1.5x as long as its width) and 4. Mesoscutum with a pair of strong bristles beyond middle of scutum (in miniae strong bristles nearer to the middle of scutum).

\section{Current status of habitat}

The semi forest area from where the collections were made are mostly disturbed by human interference.

\section{Dipara mohanae sp. nov.}

(Figs. 7-8)

\section{Material examined:}

Holotype: Female, 16.xi.1996, Thiruvannur, Kozhikode, Kerala, Coll. K. Raj Mohana (\#ZSIC 856).

\section{Distribution}

Kozhikode (Kerala) $11^{0} 13^{\prime}$ Latitude and $75^{\circ} 48^{\prime}$ Longitude. The specimen was collected by sweep net from mixed crop area in the city limits.

\section{Etymology}

The species is named after Dr. (Mrs.) Raj Mohana who collected the specimen.

\section{Diagnostic characters:}

Female: Length $1.5 \mathrm{~mm}$. Head and mesosoma yellowish-brown; eye grey with a dull black spot; ocelli reflecting yellow; scape, pedicel and anellus pale brownish-yellow; F2 and F3 light brown; F4, F5 and F6 dark brown; F7 and clava whitish-yellow. Fore and hind coxa whitish-yellow; mid coxa pale brown; remaining parts of legs pale brownish-yellow; metasoma brown with epipygium and petiole pale brownish-yellow, ovipositor sheath dark brown; setae of head, mesosoma and of wings dark brown. Pubescence pale yellow.

Head: broader than mesosoma in dorsal view (36:20); frons weakly reticulate on upper part, distinctly reticulate on other regions; scrobe moderately depressed, transversely striate-reticulate; head in anterior view 1.16x as wide as its length (14:12); in dorsal view head width $3.7 x$ its median dorsal length; eyes slightly diverging on ventral side; POL 1.23x OOL; clypeus slightly wider than long; gena rounded posteriorly; malar sulcus distinct; maximum diameter of eye in profile $2.75 \mathrm{x}$ length of malar sulcus; face below antennal toruli punctate; vertex with three pairs of setae: one pair near eye margin on either side and third pair behind hind ocelli; occiput abruptly vertical posteriorly and slightly concave; scrobe moderately deep, transversely striate-

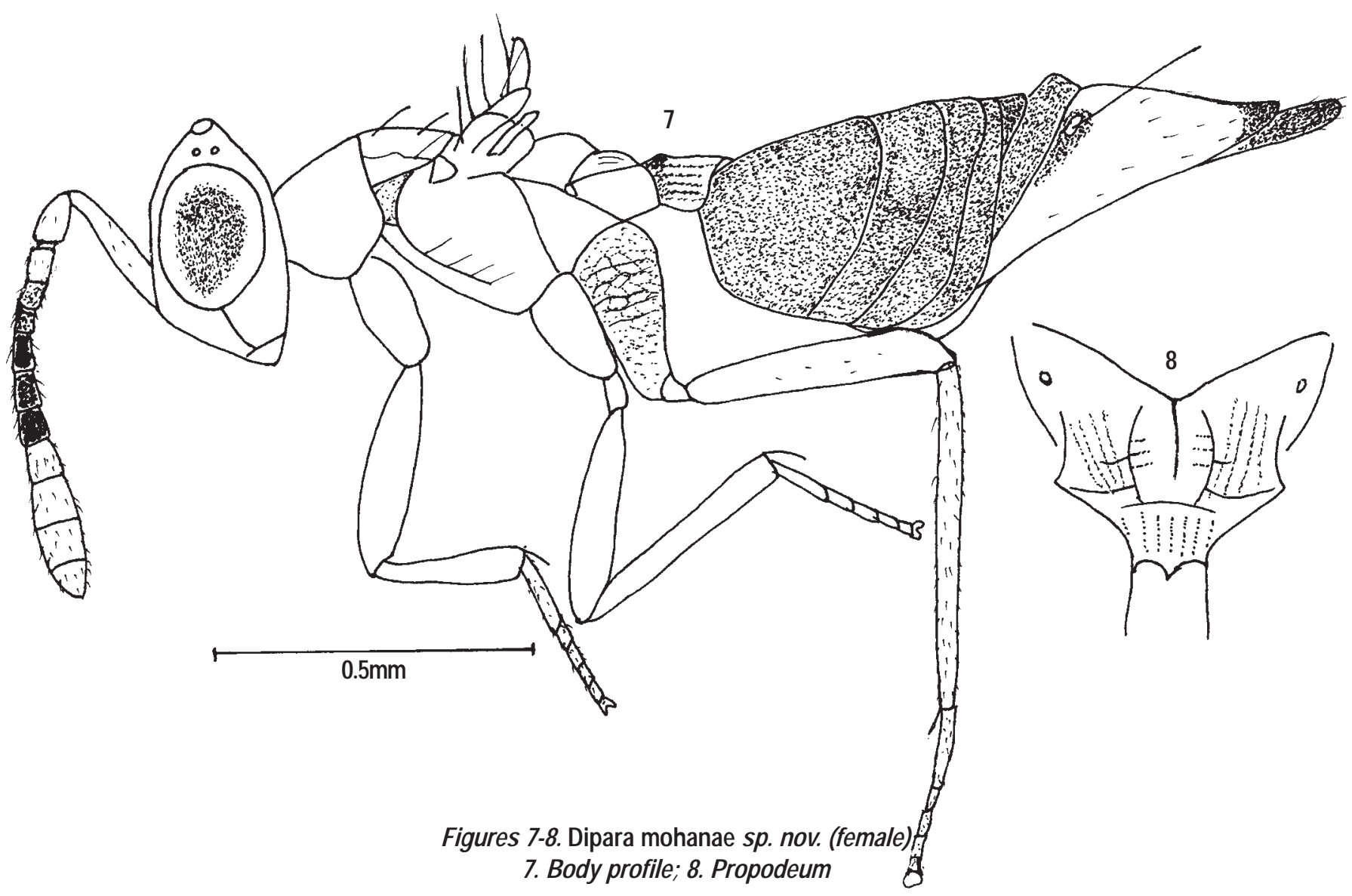


reticulate, not reaching front ocellus, margins ecarinate; parascrobal area transversely striate-reticulate. Antenna inserted slightly below level of ventral margin of eyes. Antennal formula 11173. Relative measurements of antennal segments (length: width) - - Scape $=22: 4 ;$ pedicel $=8: 5 ; \mathrm{F} 1=5: 4 ; \mathrm{F} 2=5: 4 ; \mathrm{F} 3$ $=4.5: 4 ; \mathrm{F} 4=6: 4 ; \mathrm{F} 6=5: 4.5 ; \mathrm{F} 7=6: 5.5 ;$ Clava $=19: 8$.

Mesosoma: Pronotum transversely striate; pronotum a little less than $2 \mathrm{x}$ as wide as its length in dorsal view (7:4); anterior part of mesoscutum with a semicircular smooth area followed by transverse reticulations; notauli complete; mesoscutum with two pairs of setae near middle level; each scapula with a strong seta on outer margin; mesoscutum $1.7 \mathrm{x}$ as long as scutellum; scutellum with two pairs of setae; area anterior to frenum faintly reticulate; mostly smooth; area posterior to frenum longitudinally striate; prepectus weakly reticulate; propodeum constricted posteriorly to form nucha, $1.25 \mathrm{x}$ as long as scutellum; propodeum with a median incomplete carina (Fig. 8); plicae present. Hind tibial spur about half as long as hind metatarsus, the latter a little shorter than combined lengths of remaining segments. Brachypterous; forewing with five long setae.

Metasoma: Smooth, length (including petiole) a little more than $1.6 \mathrm{x}$ length of mesosoma; petiole $1.25 \mathrm{x}$ as long as its width in dorsal view, longitudinally striate; tergites as in Figure 7; each circus with a long seta. T1 a little shorter than combined length of tergites 2-6; epipygium subequal in length of T1.

Male: Unknown.

Host: Unknown.

\section{Discussion}

Dipara canadensis Hedqvist resembles this new species in the nature of propodeum, nature of striae after frenal line etc. However $D$. canadensis differs from D. mohanae in having: 1 . Metasoma as long as head and mesosoma combined (in mohanae metasoma longer than head and mesosoma combined); 2. Petiole as long as wide (in mohanae petiole $1.25 \mathrm{x}$ as long as wide); 3 . mid coxa white (in mohanae mid coxa pale brown) and; 4 . Malar space nearly as the breadth of an eye (in mohanae malar space distinctly shorter than eye breadth).

\section{Current status of habitat}

The mixed crop area from where the specimen was collected is a disturbed area by human interference.

\section{Acknowledgements}

We are grateful to the authorities of University of Calicut for providing the facilities to carry out this research.

\section{References}

Boucek, Z. (1988). Australasian Chalcidoidea (Hymenoptera) C.A.B. International, Wallingford, U.K. 832 pp.

Boucek, Z., B.R. Subba Rao and S.I. Farooqi (1978). A preliminary review of Pteromalidae (Hymenoptera) of India and adjacent countries. Oriental Insects. 12: 433-467.

Farooqi, S.I. and B.R. Subba Rao (1986). Family Pteromalidae. pp. 279-306. In: B.R. Subba Rao and M. Hayat (Eds.). The Chalcidoidea (Insecta: Hymenoptera) of India and adjacent countries. Oriental Insects. 20: 1-430.

Graham, M.W.R.de V. (1969). The Pteromalidae of North Western Europe (Hymenoptera: Chalcidoidea). Bulletin of the British Museum of Natural History Entomology Supplement 16: 1-908.

Hedqvist, K.-J. (1969). New genera and species of Diparini with notes on the tribe (Hym. Chalcidoidea). Entomologisk Tidskrift Arq 90.H.34: 174-202.

Walker, F. (1833). Monographia Chalcidum (Continued). Entomology Monthly Magazine 1: 115-142; 367-384.

\section{Key to Indian species of Dipara (based on females)}

1. Macropterous (Fig. 4); propodeum without median carina (Fig. 6) miniae sp. nov.

1A Brachypterous (Figs. 1 and 7); propodeum with a median carina (Figs. 2 and 8 ) ...................

2. Forewing reaching base of petiole; hind coxa reticualte (Fig. 1); POL equal to OOL; basal part of scape darker in side view; F6 whitish-yellow .................................................................... keralensis sp. nov.

2A Forewing not reaching base of petiole; hind coxa striate-reticulate on dorsal side (Fig. 7); POL 1.23x OOL; scape uniformly brownish-yellow; F6 dark brown mohanae sp. nov. 